\title{
Validity of a practitioner-administered observational tool to measure physical activity, nutrition, and screen time in school-age programs
}

Rebekka M Lee ${ }^{1 *}$, Karen M Emmons², Cassandra A Okechukwu', Jessica L Barrett ${ }^{1}$, Erica L Kenney ${ }^{1}$, Angie L Cradock ${ }^{1}$, Catherine M Giles ${ }^{1}$, Madeleine E deBlois ${ }^{1}$ and Steven L Gortmaker ${ }^{1}$

\begin{abstract}
Background: Nutrition and physical activity interventions have been effective in creating environmental changes in afterschool programs. However, accurate assessment can be time-consuming and expensive as initiatives are scaled up for optimal population impact. This study aims to determine the criterion validity of a simple, low-cost, practitioner-administered observational measure of afterschool physical activity, nutrition, and screen time practices and child behaviors.
\end{abstract}

Methods: Directors from 35 programs in three cities completed the Out-of-School Nutrition and Physical Activity Observational Practice Assessment Tool (OSNAP-OPAT) on five days. Trained observers recorded snacks served and obtained accelerometer data each day during the same week. Observations of physical activity participation and snack consumption were conducted on two days. Correlations were calculated to validate weekly average estimates from OSNAP-OPAT compared to criterion measures. Weekly criterion averages are based on 175 meals served, snack consumption of 528 children, and physical activity levels of 356 children.

Results: OSNAP-OPAT validly assessed serving water $(r=0.73)$, fruits and vegetables $(r=0.84)$, juice $>40 z(r=0.56)$, and grains $(r=0.60)$ at snack; sugary drinks $(r=0.70)$ and foods $(r=0.68)$ from outside the program; and children's water consumption ( $r=0.56$ ) (all $p<0.05$ ). Reports of physical activity time offered were correlated with accelerometer estimates (minutes of moderate and vigorous physical activity $r=0.59, p=0.02$; vigorous physical activity $r=0.63, p=0.01$ ). The reported proportion of children participating in moderate and vigorous physical activity was correlated with observations $(r=0.48, p=0.03)$, as were reports of computer $(r=0.85)$ and TV/movie $(r=0.68)$ time compared to direct observations (both $p<0.01)$.

Conclusions: OSNAP-OPAT can assist researchers and practitioners in validly assessing nutrition and physical activity environments and behaviors in afterschool settings.

Trial registration: Phase 1 of this measure validation was conducted during a study registered at clinicaltrials.gov NCT01396473.

Keywords: Nutrition, Physical activity, Children, Screen time, Afterschool, Out-of-school time, Validation, Measurement

\footnotetext{
* Correspondence: rlee@hsph.harvard.edu

${ }^{1}$ Harvard School of Public Health, Social and Behavioral Sciences,

677 Huntington Avenue, Boston, MA 02115, USA

Full list of author information is available at the end of the article
} 


\section{Introduction}

Public health researchers and practitioners have made the goals of increasing physical activity and improving healthy eating among youth a major national priority, recently through Michelle Obama's Let's Move Campaign [1]. These objectives are important given the rapid increase in childhood obesity in the United States, especially among Black and Latino children and those from economically disadvantaged backgrounds [2]. While current guidelines recommend children be physically active for at least 60 minutes each day, less than half of American children meet these standards [3-5]. Additionally, children seldom meet national dietary guidelines [6] and consumption of foods and drinks such as unhealthy snacks and sugary drinks has increased in recent years [7]. High obesity rates, low physical activity levels, and poor nutrition in childhood are all risk factors for chronic disease and higher obesity rates in adulthood [1].

Some of the most impactful strategies for improving youth activity and diet aim to create changes in school and afterschool environments. Interventions targeting these environments have been effective at increasing children's physical activity and fitness [8-12], improving foods and beverages served and consumed by children [13-15], and decreasing obesity prevalence [13]. However, measuring physical activity and dietary intake with "gold standard" measures such as weighed plate waste and accelerometry requires training, time, and a substantial cost burden $[16,17]$. By contrast, lower cost surveillance measures for assessing trends in children's physical activity and diet have typically relied on child and parent reports, which are subject to recall bias and have limited evidence for criterion validity [18-20]. While observational protocols have been developed for researchers to assess nutrition and physical activity among children in educational settings with less time and cost burden than "gold standard" measures $[21,22]$, there has been limited focus on developing valid measures that practitioners can use. There is a need for tools teachers or afterschool staff can administer to assess program performance and evaluate progress as interventions are implemented. Measures that do not rely on trained research staff are also valuable for ongoing surveillance to simply and accurately track trends in program practices and child outcomes over time. In this paper, we aim to determine if a simple, low-cost, program-level, observational measure completed by afterschool program staff can validly assess afterschool physical activity and nutrition practices and child behaviors.

\section{Methods}

\section{Design}

We conducted this study in two phases. In phase 1 , we tested the criterion validity of the observational practice assessment tool (OPAT) at follow-up data collection of the Out-of-School Nutrition and Physical Activity (OSNAP) randomized controlled trial in spring 2011 [15]. Data were collected in 20 Boston afterschool programs, 10 of which participated in the OSNAP nutrition and physical activity intervention. After the criterion validity of the original items was assessed, we tested nine revised items among 15 programs in two other Massachusetts cities in fall 2012 (Phase 2).

During both phases, afterschool staff completed OSNAPOPAT during one week (up to five weekdays), and trained research staff collected concurrent criterion observational and physical activity monitor data. Program directors completed a written informed consent form and received $\$ 25$ as compensation for completing the protocol. Parents (or guardians) completed written informed consent forms for collection of individual-level child data. The study was approved by the Harvard School of Public Health Office of Human Research Administration.

The OSNAP-OPAT items were focused on measuring the 10 OSNAP intervention goals: provide all children with at least 30 minutes of moderate to vigorous physical activity every day; offer 20 minutes of vigorous physical activity 3 times per week; do not serve sugary drinks; do not allow sugary drinks to be brought in during program time; offer water as a drink at snack every day; offer a fruit or vegetable option every day at snack; when serving grains (like bread, crackers, and cereals), serve whole grains; do not serve foods with trans fat; limit computer and digital device time to homework or instructional only; and eliminate use of commercial broadcast and cable TV and movies.

\section{Measures}

\section{Program characteristics}

Parents reported child race/ethnicity, age, and gender on the consent form. Attendance was recorded during each day of data collection to determine program size. We obtained the proportion of students who were eligible for free or reduced price meals at the school hosting the program (or the school nearest the program) from administrative records. In phase 1 , directors reported their years of experience, age, gender, education, hours of employment, race/ethnicity, and the number of staff at the program on a questionnaire.

\section{Out-of-school nutrition and physical activity observational practice assessment tool (OSNAP-OPAT)}

Study staff designed a paper and pencil daily observational practice assessment tool to align with the OSNAP intervention goals, which included items on physical activity, foods, beverages, and screen time (See Additional file 1 for complete tool). Two research assistants and two afterschool directors piloted the tool during afterschool program time, reviewing the usefulness of the 
instructions and glossary as well as the clarity of question wording and feasibility of completion. They reported that completing the OSNAP-OPAT for the program took 5-10 minutes to complete each day. Research assistants introduced OSNAP-OPAT to program directors before the program began on the Monday of each data collection week. Directors were instructed to answer the questions to the best of their ability based on what happened during the afterschool day. They were given a glossary with key physical activity and nutrition terms and a page for notes to gather input from other staff (Additional file 1).

In phase 1, OSNAP-OPAT was completed on five consecutive days by directors at 20 programs. Six items on program-provided foods and beverages served and three items on program screen time had dichotomous (yes/no) response categories. For each food or beverage offered, consumption was measured on a four-point scale. Two items on foods and beverages brought in from outside the snack program had four response categories corresponding to the number of children who consumed them. Five physical activity items measured the amount of time offered to children with dichotomous (yes/no) response categories for each question, while one item on the proportion of children participating in physical activity had five response categories. In phase 2, new items were fielded at 15 different programs. We tested six revised OSNAP-OPAT items on children's physical activity with five response categories and three new dichotomous questions about serving sugar-sweetened beverages, 100\% juice, and 100\% juice $>4 \mathrm{oz}$.

\section{Criterion measures}

Physical activity Child physical activity levels during the afterschool period were measured by Actigraph accelerometer (Models GT1M, GT3X, and GT3X+), considered a reliable and valid criterion measure for physical activity (see Table 1) $[17,23,24]$. Research assistants distributed accelerometers to participants on each day of data collection. During phase 1, accelerometer data were collected on five days (Monday-Friday); in phase 2, programs were typically offered on fewer days and, thus, accelerometer data were collected on threefive days. Accelerometers were fastened on the hip with an adjustable belt and children were instructed to wear them for the entire afterschool program period, except during swimming. We converted accelerometer intensity counts per one-minute epoch to total minutes of moderate and vigorous physical activity (MVPA) and vigorous physical activity (VPA) (i.e., including every minute above the corresponding threshold) during the afterschool period according to methods used in analysis of national surveillance data, using cut points and algorithms adapted from Troiano and colleagues $[4,10]$.
We assessed child participation in physical activity with structured observations according to a modified System for Observing Play and Leisure Activity in Youth (SOPLAY) protocol during all physical activity periods on two days at each program [26,27]. At two-minute intervals, research assistants rotated through physical activity spaces scanning from left to right and using a counter to tally the number of children engaged in sedentary, moderate, or vigorous physical activity.

Nutrition The criterion measure for all nutrition outcomes was direct observation by trained observers (see Table 1) $[28,29,31]$. Research assistants recorded all food and beverage items served at snack, along with size, type, and brand, on 5 days at each program. Snack consumption of all consented children was recorded via direct observation and digital photography on two days at each program. Data collectors assessed whether children received each of the snack components and how much of each food or drink they consumed (e.g. none, some, most, or all). This observation measure was highly correlated with a weighted plate waste protocol [29]. The number of children who consumed foods and beverages from outside the program snack (e.g. from home, vending machines) were also recorded each day.

We obtained nutrition information for all foods and beverages observed from Boston Food and Nutrition Services, manufacturer's websites, or from similar product listings in the US Department of Agriculture (USDA) Nutrient Database. Classification of foods and beverages was based the OSNAP intervention goals. Water served refers to water that was distributed as part of the program snack either via pitchers or coolers and cups in the snack area. It does not include water the children drank from water fountains or coolers outside the snack area or period. Sugary drinks were defined as beverages with added sugar and 100\% juice greater than 4oz. Foods with trans fats were defined as items containing "partially hydrogenated" oil on ingredients list. Whole grains were defined as foods containing a whole grain as the first ingredient. Fruits and vegetables included any fresh, frozen, canned, or dried produce. Grain products included breads, cereals, crackers, etc.

Screen time Research assistants completed a minuteby-minute $\log$ of each program day that included the number of minutes children were offered screen time (e.g. computers; television/movies).

\section{Statistical analysis}

We summarized daily estimates of all OSNAP-OPAT items and criterion measures into weekly averages for each program. Data from 5 days of observations were used except for cases where fewer days were observed 
Table 1 Criterion measures used to validate the Out-of-School Nutrition and Physical Activity Observational Practice Assessment Tool (OSNAP-OPAT)

\begin{tabular}{|c|c|c|c|c|c|}
\hline Measure & $\begin{array}{l}\text { Weekly } \\
\text { mean (SD) }\end{array}$ & Psychometric properties & Phase & Days & $\begin{array}{l}\text { Corresponding OSNAP-OPAT } \\
\text { items }\end{array}$ \\
\hline \multirow{2}{*}{$\begin{array}{l}\text { Minutes of moderate and vigorous } \\
\text { physical activity per day via } \\
\text { Actigraph accelerometer from all } \\
\text { valid days }^{\text {a }}\end{array}$} & \multirow[t]{2}{*}{$15.30(8.37)$} & $\begin{array}{l}\text { High reliability }(I C C=0.80) \text { over } 4 \\
\text { days for children's overall physical } \\
\text { activity [23] }\end{array}$ & \multirow[t]{2}{*}{$1 \& 2$} & \multirow[t]{2}{*}{5} & $\begin{array}{l}\text { How many minutes do you think the } \\
\text { typical child at your program was } \\
\text { physically active today? }\end{array}$ \\
\hline & & $\begin{array}{l}\text { Evidence for validity of children's } \\
\text { physical activity counts compared } \\
\text { to doubly labeled water and } \mathrm{VO}_{2} \\
\max [17,24,25]\end{array}$ & & & $\begin{array}{l}\text { What is the least amount of physical } \\
\text { activity time that was offered to any } \\
\text { group of children today? }\end{array}$ \\
\hline
\end{tabular}

Minutes of vigorous physical activity per day via Actigraph accelerometer from all valid days ${ }^{\mathrm{a}}$

Percent of children engaged in moderate or vigorous physical activity during physical activity time via SOPLAY observations

Direct observation of proportion of days items served at snack, including brand and size linked with nutrient database

Proportion of snack component(s) consumed according to direct observation and photography (Coded None 0, some 1, most 2, all 3)

Direct observation of proportion of days screen time offered during the afterschool program

TV: $0.03(0.08)$

High interrater reliability

$0.14(0.23)$

ICC $=0.78-0.92$ [29]

Valid in comparison to weighed plate waste protocol

Food items ICC $=0.86-0.94$

Self-served water ICC = 0.47-0.52 [29]

High interrater reliability of young children's time watching television $r=0.96[30]$

Computer:

$0.43(0.40)$

Direct observation of number of children per day consuming foods and beverages brought in from outside the program snack

Sugary drinks: $2.11(2.09)$

High interrater agreement (87\%) for item identification in elementary students' home-packed lunches [31]
$1 \& 2 \quad 5 \quad$ How many minutes do you think the typical child at your program was engaged in vigorous physical activity (i.e. activity more than a walk) today?

What is the least amount of vigorous physical activity time that was offered to any group of children today?

How many children do you think were active when they attended physical activity time?

Was a fruit or vegetable offered at snack?

Were grains served at snack?

If grains were served at snack, were whole grains served?

Was water served (with a pitcher or from a cooler) at snack?

Was 100\% juice served at snack?

If $100 \%$ juice was served at snack, was it served in a container greater than $40 z$ ?

$1 \& 2 \quad 2 \quad$ For the children who were served water, how much do you think they drank? 
using the criterion measures (e.g. SOPLAY, snack intake) or programs ran on fewer than 5 days per week. To assess the criterion validity of OSNAP-OPAT, we calculated Pearson correlations comparing the weekly averages estimated by the OSNAP-OPAT to corresponding estimates from the criterion measures described in the methods and in Table 1. Criterion validity is the extent to which a measure performs like a "gold standard" measure, under the assumption that prediction, not explanation, indicates accuracy [20]. Correlations between 0.40 and 0.60 were considered moderate; those over 0.60 were considered strong.

All analyses were performed in 2013 using SAS 9.3 (SAS Institute, Cary, NC). For physical activity outcomes, we compared weekly average estimates from OSNAP-OPAT to weekly averages of SOPLAY observation data and accelerometer estimates. Midpoints of ranges in OSNAPOPAT physical activity 5-point scales were used when computing minutes per day; for the $60+$ minute category, 67.5 was used (see Additional file 1 for scale). Three days when swimming was offered and accelerometers were taken off were excluded from activity analyses. For nutrition outcomes, we compared weekly average estimates from OSNAP-OPAT to data collected from snack observations and the plate waste protocol. Weekly averages for screen time and outside food and beverage items from OSNAP-OPAT were compared to weekly averages from direct observations. We conducted linear regressions to determine if intervention status in phase 1 was associated with the accuracy of responses.

For those OSNAP-OPAT items with at least a moderate correlation among weekly estimates $(\mathrm{r}>/=0.40)$, we calculated Pearson correlations using only one day of OSNAPOPAT data to predict average weekly criterion outcomes. For each day of the week (Monday-Friday), daily OSNAPOPAT estimates were compared to the average weekly criterion measure, and the average Pearson correlations across the days were calculated.

\section{Results}

During phase 1, directors from 18 programs completed the practice assessment on five days each. One program completed OSNAP-OPAT on four days and another on only three days. In phase 2 , most programs ran MondayThursday; thus, practice assessment and criterion data were usually collected on four days. Table 2 shows characteristics of the afterschool programs and the children who attended the programs. The typical program served about 50 children each day. Programs in this sample served more children of color (78\%) than white children $(22 \%)$ and $80 \%$ students at the school where the programs were based qualified for free/reduced price lunch.

Directors who completed OSNAP-OPAT in phase 1 had an average of $3.5(\mathrm{SD}=4.3)$ years in their role and an average age of $36(\mathrm{SD}=10.6)$. Thirteen of 20 directors
Table 2 Characteristics of afterschool programs and children where the Out-of-School Nutrition and Physical Activity Observational Practice Assessment Tool (OSNAP-OPAT) was completed

\begin{tabular}{|c|c|c|}
\hline Program characteristics $_{a}$ & Phase $1(\mathrm{~N}=20)$ & Phase $2(\mathrm{~N}=15)$ \\
\hline $\begin{array}{l}\text { Average daily attendance } \\
\text { per site, mean (SD) }\end{array}$ & $55.0(49.9)$ & $44.6(17.9)$ \\
\hline \multicolumn{3}{|l|}{ Sponsoring agency, $n$ (\%) } \\
\hline YMCA & $8(40.0 \%)$ & $2(13.3 \%)$ \\
\hline Boys \& Girls Club & $4(20.0 \%)$ & $0(0.0 \%)$ \\
\hline Community Centers & $5(25.0 \%)$ & $3(20.0 \%)$ \\
\hline School & $3(15.0 \%)$ & $10(66.7 \%)$ \\
\hline $\begin{array}{l}\text { Proportion of students at the } \\
\text { school where the program is } \\
\text { based who qualify for free or } \\
\text { reduced price meals }\end{array}$ & $81.6 \%$ & $79.2 \%$ \\
\hline Child characteristics $_{b}$ & Phase $1(\mathrm{~N}=596)$ & Phase $2(N=389)$ \\
\hline Age (yrs.), mean (SD) & $7.8(1.8)$ & $8.6(1.8)$ \\
\hline Male, (\%) & $50.8 \%$ & $50.7 \%$ \\
\hline \multicolumn{3}{|l|}{ Racelethnicity, (\%) } \\
\hline White & $9.2 \%$ & $34.2 \%$ \\
\hline Black/African American & $29.5 \%$ & $5.4 \%$ \\
\hline Hispanic/Latino & $29.7 \%$ & $31.1 \%$ \\
\hline Asian & $4.2 \%$ & $1.3 \%$ \\
\hline Cape Verdean & $2.7 \%$ & $1.6 \%$ \\
\hline Black Hispanic & $3.2 \%$ & $0.0 \%$ \\
\hline Multiracial & $4.9 \%$ & $14.0 \%$ \\
\hline Missing & $16.6 \%$ & $12.4 \%$ \\
\hline
\end{tabular}

a) The average daily attendance was recorded at each site by research assistants during the week of data collection. The proportion of children who qualify for free or reduced price meals was collected via administrative records. Programs that were non-school based used data from the closest school as a proxy.

b) Child characteristics were reported by parents on consent forms.

were women and 16 had a college degree. On average, the directors worked at the program 33 hours per week $(\mathrm{SD}=9.4)$; some worked as full-time benefited employees, while other worked part-time.

\section{Phase 1}

Pearson correlations summarizing the criterion validity of each OSNAP-OPAT item are reported in Table 3. Reported physical activity participation levels were correlated with estimates of the proportion of children participating in MVPA via SOPLAY $(\mathrm{r}=0.48, \mathrm{p}=0.03)$. Directors' reports of serving water, fruits and vegetables, and grains at snack time were significantly correlated with observations by trained data collectors $(r=0.73, r=0.84, r=0.60$ respectively; all $\mathrm{p}<0.01$ ). There was a moderate correlation between reports and observations of whole grains being served $(\mathrm{r}=0.43, \mathrm{p}=0.06)$. Additionally, directors validly reported how much children drank when they were served 
Table 3 Criterion validity of the Out-of-School Nutrition and Physical Activity Observational Practice Assessment Tool (OSNAP-OPAT)

\begin{tabular}{|c|c|c|c|c|c|c|c|}
\hline Item & $N^{a}$ & $\begin{array}{l}\text { Weekly } \\
\text { mean (SD) }\end{array}$ & $\begin{array}{l}\text { Validation } \\
\text { criterion measure }\end{array}$ & $\begin{array}{l}\text { Pearson } \\
\text { correlation (week) }\end{array}$ & $P$ value & 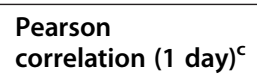 & Range \\
\hline \multicolumn{8}{|l|}{ Physical Activity } \\
\hline $\begin{array}{l}\text { How many children do you think } \\
\text { were active when they attended } \\
\text { physical activity time? (0-4 scale: } \\
0 \text { Not offered, } 1 \text { Few, } 2 \text { Some, } 3 \\
\text { Most, } 4 \text { All) }\end{array}$ & 20 & $2.54(0.39)$ & SOPLAY & 0.48 & 0.03 & 0.28 & $0.09-0.50$ \\
\hline $\begin{array}{l}\text { How many minutes do you think } \\
\text { the typical child at your program } \\
\text { was physically active today? } \\
\text { (Mins) }\end{array}$ & 15 & $34.40(12.31)$ & Accelerometer & 0.43 & 0.11 & 0.23 & $-0.17-0.44$ \\
\hline $\begin{array}{l}\text { What is the least amount of } \\
\text { physical activity time that was } \\
\text { offered to any group of children } \\
\text { today? (Mins) }\end{array}$ & 15 & $21.13(14.88)$ & Accelerometer & 0.59 & 0.02 & 0.33 & $-0.19-0.62$ \\
\hline $\begin{array}{l}\text { How many minutes do you think } \\
\text { the typical child at your program } \\
\text { was engaged in vigorous } \\
\text { physical activity (i.e. activity more } \\
\text { than a walk) today? (Mins) }\end{array}$ & 15 & 26.59 (13.46) & Accelerometer & 0.43 & 0.11 & 0.21 & $0.09-0.36$ \\
\hline $\begin{array}{l}\text { What is the least amount of } \\
\text { vigorous physical activity time } \\
\text { that was offered to any group of } \\
\text { children today? (Mins) }\end{array}$ & 15 & $18.29(14.41)$ & Accelerometer & 0.63 & 0.01 & 0.42 & $0.13-0.61$ \\
\hline \multicolumn{8}{|l|}{ Nutrition } \\
\hline $\begin{array}{l}\text { Was a fruit or vegetable offered } \\
\text { at snack? (Proportion) }\end{array}$ & 20 & $0.59(0.29)$ & Observation & 0.84 & 0.0001 & 0.52 & $0.38-0.66$ \\
\hline $\begin{array}{l}\text { Were grains served at snack? } \\
\text { (Proportion) }\end{array}$ & 20 & $0.68(0.34)$ & Observation & 0.60 & 0.005 & 0.47 & $0.25-0.56$ \\
\hline $\begin{array}{l}\text { If grains were served at snack, } \\
\text { were whole grains served? } \\
\text { (Proportion) }\end{array}$ & 20 & $0.47(0.32)$ & Observation & 0.43 & 0.06 & 0.32 & $0.17-0.50$ \\
\hline $\begin{array}{l}\text { Was water served (with a pitcher } \\
\text { or from a cooler) at snack? } \\
\text { (Proportion) }\end{array}$ & 20 & $0.70(0.41)$ & Observation & 0.73 & 0.0003 & 0.66 & $0.59-0.72$ \\
\hline $\begin{array}{l}\text { How many kids consumed } \\
\text { sugary drinks from outside the } \\
\text { snack program (e.g. vending, } \\
\text { home, etc.) during the } \\
\text { afterschool day? (0-3 scale: } 0 \\
\text { None, } 1 \text { Few, } 2 \text { Some, } 3 \text { Many) }\end{array}$ & 20 & $0.74(0.78)$ & Observation & 0.70 & 0.0005 & 0.62 & $0.54-0.70$ \\
\hline $\begin{array}{l}\text { How many kids consumed food } \\
\text { from outside the snack program } \\
\text { during the afterschool day? } \\
\text { (0-3 scale: } 0 \text { None, } 1 \text { Few, } \\
2 \text { Some, } 3 \text { Many) }\end{array}$ & 20 & $1.06(0.65)$ & Observation & 0.68 & 0.001 & 0.65 & $0.48-0.82$ \\
\hline $\begin{array}{l}\text { Was } 100 \% \text { juice served at snack? } \\
\text { (Proportion) }\end{array}$ & 15 & $0.29(0.32)$ & Observation & 0.50 & 0.06 & 0.42 & $0.17-0.82$ \\
\hline $\begin{array}{l}\text { If } 100 \% \text { juice was served at } \\
\text { snack, was it served in a } \\
\text { container greater than } 40 z ? \\
\text { (Proportion) }\end{array}$ & 15 & $0.25(0.31)$ & Observation & 0.56 & 0.03 & 0.59 & $0.33-0.86$ \\
\hline For the children who were & 20 & $0.64(0.36)$ & Plate waste & 0.56 & 0.01 & 0.49 & $0.39-0.60$ \\
\hline
\end{tabular}


data since most programs offered the targeted $30 \mathrm{mi}-$ nutes of daily physical activity and little variation existed in responses. When we changed items to a scale with five time intervals, physical activity items were significantly correlated with corresponding accelerometer estimates. Afterschool directors' reports of the least amount of physical activity offered to any group of children were more highly correlated with children's objectively measured physical activity levels than their reports of the physical activity of a typical child at the program. In phase 2 , splitting a single sugary beverage question into three distinct items on juice, large juice $(>4 \mathrm{oz})$, and beverages with added sugar yielded valid assessments.

To date, limited research has sought to develop valid nutrition and physical activity measures that are easy for practitioners to use in free-living settings like afterschool programs with limited training and at low cost [21]. However, researchers have begun creating measures designed for early childcare staff $[32,33]$. The current study builds on this evidence base by using strong criterion measures over the course of one week to obtain a more precise estimate of nutrition and physical activity practices and behaviors. It also uses repeated assessment data to determine how one day of data performs in comparison to weekly criterion measures. While some items were significantly correlated with the criterion with one day of data, as expected the ranges of these estimates were wide. Whenever possible, researchers and program staff should use weekly averages, rather than one-day estimates. OSNAP-OPAT is low cost and requires minimal staff time to complete. Plus, the instructions for utilizing the measure are built into the tool, rather than requiring the extra expense and time of training. Its user-friendly format can help afterschool staff take action to improve their current practices. The measure and companion tools for identifying areas for improvement and developing action plans are available for free at www.osnap.org.

This study has several limitations. OSNAP-OPAT items completed by directors could not accurately assess the serving of snacks with trans fats nor children's consumption of foods and beverages other than water. These items have been removed from the final measure. We encourage future research on the best way to capture accurate data on these items from practitioners in the field. The generalizability of our findings is limited due to the small sample of programs all located in Massachusetts who agreed to participate in a nutrition and physical activity intervention. However, the instrument was tested in programs sponsored by a range of organizations and in low income, racially diverse settings. While we were able to establish criterion validity-the extent to which OSNAPOPAT performs similarly to "gold standard" measures of trained direct observation and accelerometry, assessing the measure's content and construct validity were outside the scope of this study. Finally, because we initialized accelerometers using one-minute epochs according to the guidelines from the National Cancer Institute to be consistent with methods used in national surveillance, we were unable to analyze shorter physical activity intervals that may have captured intermittent physical activity. Recent research indicates that the Actigraph accelerometers and one-minute intervals capture children's energy expenditure well compared to room calorimeters and doubly labeled water methods [25].

\section{Conclusion}

OSNAP-OPAT is a measure that can be used to validly assess program performance as interventions are implemented and evaluated in real world afterschool settings. This brief assessment tool will help researchers and practitioners gain an accurate assessment of afterschool program practices and child behaviors and target specific areas for improvement as they initiate and evaluate obesity prevention initiatives.

\section{Additional files}

Additional file 1: Out-of-school Nutrition and Physical Activity (OSNAP) Observational Practice Assessment Tool (OPAT).

Additional file 2: Items not retained in final tool.

\section{Abbreviations}

OSNAP-OPAT: Out-of-school nutrition and physical activity observational practice assessment tool; MVPA: Moderate and vigorous physical activity [the measure]; VPA: Vigorous physical activity; OSNAP: Out-of-School Nutrition and Physical Activity Initiative [the intervention]; USDA: United States Department of Agriculture; SOPLAY: System for Observing Play and Leisure Activity in Youth; FV: Fruit and vegetable; SD: Standard deviation; N: Number; Mins: Minutes; ICC: Intraclass correlation; R: Correlation coefficient; Yrs: Years.

\section{Competing interests}

The authors declare they have no competing interests.

\section{Authors' contributions}

$\mathrm{RL}$ led the measure development, study design, data collection, analysis, interpretation, and drafting of the manuscript. KE and CO contributed substantially to the analysis and interpretation of the data. JL and EK participated in the study design and analysis. AC and CG participated in the conception, study design, and interpretation of results. MD contributed to measure development, study design, and data collection. SG served as the senior author and PI on the study, contributed to measure development, study design, analysis, and interpretation. All authors contributed to drafting and revising the manuscript and approved the final draft.

\section{Acknowledgements}

This work was supported by: the Donald and Sue Pritzker Nutrition and Fitness Initiative, Cooperative Agreement 1U48DP001946 (including NOPPREN) from the CDC Prevention Research Centers Program, the Robert Wood Johnson Foundation (No. 66284), grant 3U01AG027669-S1, and K05CA124415. This work is solely the responsibility of the authors and does not represent the official views of the CDC.

We thank our research assistants for their help collecting data and the enthusiastic afterschool staff for their willingness to open their doors to this research. We also thank the Massachusetts Department of Public Health for their help recruiting programs for the second phase of this study and Arthur Sobol for reviewing SAS programs. 


\section{Author details}

${ }^{1}$ Harvard School of Public Health, Social and Behavioral Sciences, 677 Huntington Avenue, Boston, MA 02115, USA. ${ }^{2}$ Kaiser Foundation Research Institute, Oakland, California.

Received: 3 July 2014 Accepted: 10 November 2014

Published online: 28 November 2014

\section{References}

1. The Surgeon General's Vision for a Healthy and Fit Nation. [http://www. surgeongeneral.gov/initiatives/healthy-fit-nation/obesityvision2010.pdf]

2. Ogden CL, Carroll MD, Curtin LR, Lamb MM, Flegal KM: Prevalence of high body mass index in US children and adolescents, 2007-2008. JAMA 2010, 303:242-249.

3. Physical Activity Guidelines for Americans. [http://www.health.gov/ paguidelines/]

4. Troiano RP, Berrigan D, Dodd KW, Masse LC, Tilert T, McDowell M: Physical activity in the United States measured by accelerometer. Med Sci Sports Exerc 2008, 40:181-188.

5. Gortmaker S, Lee R, Cradock A, Sobol A, Duncan D, Wang Y: Disparities in Youth Physical Activity in the United States: 2003-2006. Med Sci Sports Exerc 2011, 44:888-893.

6. Muñoz KA, Krebs-Smith SM, Ballard-Barbash R, Cleveland LE: Food Intakes of US Children and Adolescents Compared With Recommendations. Pediatrics 1997, 100:323-329.

7. Piernas C, Popkin BM: Trends In Snacking Among U.S. Children. Health Aff 2010, 29:398-404.

8. Dzewaltowski D, Rosenkranz R, Geller K, Coleman K, Welk G, Hastmann T, Milliken G: HOP'N after-school project: an obesity prevention randomized controlled trial. Int J Behav Nutr Phys Act 2010, 7:90.

9. Gutin B, Yin Z, Johnson M, Barbeau P: Preliminary findings of the effect of a 3-year after-school physical activity intervention on fitness and body fat: The Medical College of Georgia Fitkid Project. Int J Pediatr Obes 2008, 3:3-9.

10. Gortmaker SL, Lee RM, Mozaffarian RS, Sobol AM, Nelson TF, Roth BA, Wiecha JL: Effect of an after-school intervention on increases in children's physical activity. Med Sci Sports Exerc 2012, 44:450-457.

11. Beets MW, Weaver RG, Moore JB, Turner-McGrievy G, Pate RR, Webster C, Beighle A: From Policy to Practice: Strategies to Meet Physical Activity Standards in YMCA Afterschool Programs. Am J Prev Med 2014, 46:281-288

12. Beets MW, Huberty J, Beighle A: Systematic Observation of Physical Activity in Afterschool Programs: Preliminary Findings From Movin' Afterschool Intervention. J Phys Act Health 2013, 10:974-981.

13. Gortmaker SL, Cheung LW, Peterson KE, Chomitz G, Cradle JH, Dart H, Fox MK, Bullock RB, Sobol AM, Colditz G, Field AE, Laird N: Impact of a school-based interdisciplinary intervention on diet and physical activity among urban primary school children: eat well and keep moving. Arch Pediatr Adolesc Med 1999, 153:975-983

14. Mozaffarian RS, Wiecha JL, Roth BA, Nelson TF, Lee RM, Gortmaker SL: Impact of an Organizational Intervention Designed to Improve Snack and Beverage Quality in YMCA After-School Programs. Am J Public Health 2010, 100:925-932

15. Giles CM, Kenney EL, Gortmaker SL, Lee RM, Thayer JC, Mont-Ferguson H, Cradock AL: Increasing Water Availability During Afterschool Snack Evidence, Strategies, and Partnerships from a Group Randomized Trial. Am J Prev Med 2012, 43:S136-S142.

16. Williamson DA, Allen HR, Martin PD, Alfonso AJ, Gerald B, Hunt A: Comparison of digital photography to weighed and visual estimation of portion sizes. J Am Diet Assoc 2003, 103:1139-1145.

17. Corder K, Ekelund U, Steele RM, Wareham NJ, Brage S: Assessment of physical activity in youth. J Appl Physiol 2008, 105:977-987.

18. Biddle SJ, Gorely T, Pearson N, Bull FC: An assessment of self-reported physical activity instruments in young people for population surveillance: Project ALPHA. Int J Behav Nutr Phys Act 2011, 8:1.

19. Magarey A, Watson J, Golley RK, Burrows T, Sutherland R, McNaughton SA, Denney-Wilson E, Campbell K, Collins C: Assessing dietary intake in children and adolescents: Considerations and recommendations for obesity research. Int J Pediatr Obes 2011, 6:2-11.

20. DeVellis RF: Scale Development: Theory and Applications. Los Angeles: Sage; 2012.
21. Ajja R, Beets MW, Huberty J, Kaczynski AT, Ward DS: The Healthy Afterschool Activity and Nutrition Documentation Instrument. Am J Prev Med 2012, 43:263-271.

22. Bower JK, Hales DP, Tate DF, Rubin DA, Benjamin SE, Ward DS: The childcare environment and children's physical activity. Am J Prev Med 2008, 34:23-29.

23. Janz KF, Witt J, Mahoney LT: The stability of children's physical activity as measured by accelerometry and self-report. Med Sci Sports Exerc 1995, 27:1326-1332.

24. Plasqui G, Westerterp KR: Physical activity assessment with accelerometers: an evaluation against doubly labeled water. Obesity 2007, 15:2371-2379.

25. Butte NF, Wong WW, Lee JS, Adolph AL, Puyau MR, Zakeri IF: Prediction of Energy Expenditure and Physical Activity in Preschoolers. Med Sci Sports Exerc 2014, 46:1216-1226.

26. McKenzie TL, Marshall SJ, Sallis JF, Conway TL: Leisure-time physical activity in school environments: an observational study using SOPLAY. Prev Med 2000, 30:70-77.

27. Saint-Maurice $P$, Welk G, Ihmels M, Krapfl J: Validation of the SOPLAY direct observation tool with an accelerometery-based physical activity monitor. J Phys Act Health 2011, 8:1108-1116.

28. Baglio ML, Baxter SD, Guinn CH, Thompson WO, Shaffer NM, Frye FHA: Assessment of interobserver reliability in nutrition studies that use direct observation of school meals. J Am Diet Assoc 2004, 104:1385-1392.

29. Kenney EL, Davison KK, Austin SB, Giles CM, Cradock AL, Lee RM, Gortmaker SL. Validity and reliability of a simple, low cost measure to quantify children's dietary intake in afterschool settings. J Acad Nutr Diet, in press.

30. DuRant RH, Baranowski T, Johnson M, Thompson WO: The relationship among television watching, physical activity, and body composition of young children. Pediatrics 1994, 94:449-455.

31. Richter SL, Vandervet LM, Macaskill LA, Salvadori MI, Seabrook JA, Dworatzek PDN: Accuracy and Reliability of Direct Observations of Home-Packed Lunches in Elementary Schools by Trained Nutrition Students. J Acad Nutr Diet 2012, 112:1603-1607.

32. Benjamin S, Neelon B, Ball S, Bangdiwala S, Ammerman A, Ward D: Reliability and validity of a nutrition and physical activity environmental self-assessment for child care. Int J Behav Nutr Phys Act 2007, 4:29.

33. Henderson KE, Grode GM, Middleton AE, Kenney EL, Falbe J, Schwartz MB: Validity of a measure to assess the child-care nutrition and physical activity environment. J Am Diet Assoc 2011, 111:1306-1313.

doi:10.1186/s12966-014-0145-5

Cite this article as: Lee et al:: Validity of a practitioner-administered observational tool to measure physical activity, nutrition, and screen time in school-age programs. International Journal of Behavioral Nutrition and Physical Activity 2014 11:145

\section{Submit your next manuscript to BioMed Central and take full advantage of:}

- Convenient online submission

- Thorough peer review

- No space constraints or color figure charges

- Immediate publication on acceptance

- Inclusion in PubMed, CAS, Scopus and Google Scholar

- Research which is freely available for redistribution 